\title{
موقف الصحافة العراقية من مشكلة الموصل
}

\author{
م. شياء محمد ظاهر عبدالرمن، كلية العلوم الانسانية، قسم التاريخ، جامعة زاخو، أقليم كوردستان العراق

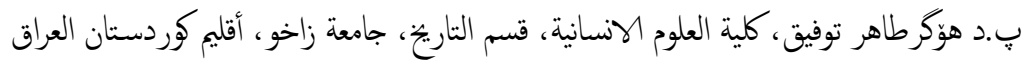

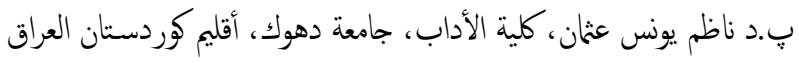

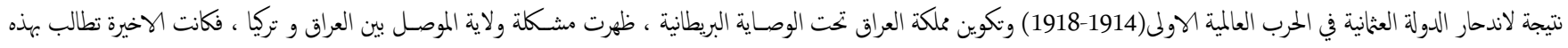

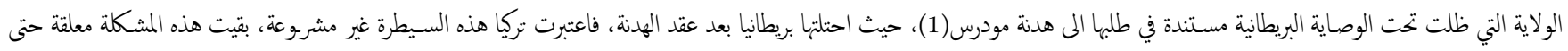

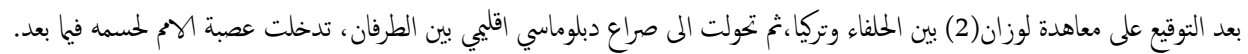

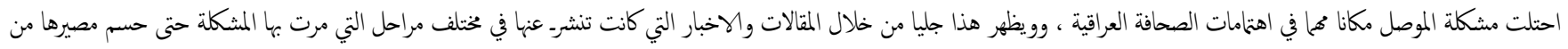

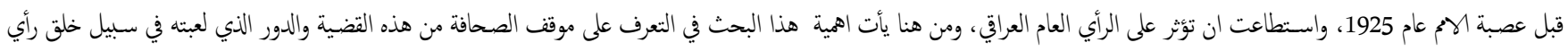
عام يساند الحجج والمطالبيب العراقية في احقية ضم الولاية اليهم. الكلمات المفتاحية: مشكلة الموصل، الكورد، الصحافة العراقية، عصبة الوم.

1 1

بعنوان(الموصل .. الموصل) بانه مع اقتزاب موعد عقد مؤتمر حول الولاية بين بريطانيا بصفها دولة منتدبة للعراق وبين تركيا، فإنها رأت أن يطلع قراءها على حقائق حول المنطقة، فتقول بانه في ملتقى الشعوب الثلاثة (العرب، والفرس، والترك) يوجد الشعب الكردي في بقعة مستطيلة، في: لورستان، وكمانشاه، وسنه وحواليها في ايران، اما في العراق العربي فنذكر اقسام اقضية بدره، ومندلي، وخانقين وقسم همم من لوائي كركك واربيل وفيها السليانية، ومن الجزيرة العليا وهضاب أرضروم التي تحتوي على اغلب أقسام ولاية وان، وأرضروم، ودياربكر، ومعمورة العزيز، وسيواس، وبتليس، وكذلك جزء من الأقسام الشالية لولاية حلب، هذه المناطق حسب الجريدة تكون البلاد الكردية "كردستان" التي فرقتها حدود المماليك الحالية (العراق، وايران، تركيا، وسوريا) وتذكر بان لو قسمت كوردستان الى ثماني نسب، فيكون نصيب العراق منه "الثنم"، وايران "ثلاثة أثمان"، وتركيا "النصف او اكثر"، لذلك تؤكد الجريدة بان العنصر العربي جغرافياً لا يجاور العنصر التركي في اقسام العراق الشالية، قتقول:" بانه اذ ما اراد سائُ ما ان يجتاز ولاية بغداد والموصل فانه يمر في طريقه بكردستان لا محال"(7). تستمر جريدة (الاستقلال) في الحديث عن ولاية الموصل وسكانها في اعدادها اللاحقة، فأشارت في عددها الصادر بتاريخ 29 كنون الثاني 1924 في مقالة لها أن لغة شعوب هذه المنطقة (العرب والكرد) هي ليست تركية، لذلك تحاول تركيا عن طريق انباع سياسة التزريك بالقضاء على لغة هذه الشعوب، فنذكر عن اللغة الكردية
واككت الصحافة العراقية أبرز مراحل هذه المشكلة وتحديداً من سنة 1923 عندما كانت هناك محادثات بين لندن وأنقرة في مدينة لوزان السويسرية لعقد معاهدة جديدة، فاحتلت مشكلة الموصل مساحة لا بأس بها من الصحافة العراقية وفي الكثر من المرات كانت الأخبار المتعلقة بهذه المشكلة تنشر في صدر الصفحة الأولى من الجرائد العراقية نظراً لأهيتها كما يبدو، فنشرت جريدة (العراق)(3) في عددها الصادر بتاريخ 20 تشرين الأول 1923 مقالة بعنوان(قضية الموصل والدنو اجل البت فيها) اشار فيها الى اهمية الولاية للعراق والتي اعتبرها "بمنزلة القلب للجسم" فان انتزت الموصل من العراق سيصبح البلد "جثة هامدة"، كما اكدت الجريدة بان العراق لن يستطيع السير في طريق الاستقلال بدون الموصل، اكبر مورد اقتصادي ستعمد عله العراق في اصلاح شؤونه المالية وغناه في المستقبل (4). اهتمت جريدة (الاستقلال)(5 بمشكة الموصل مثل باقي زميلاتها من الصحف رك العراقية، وهي وان كانت تختلف عن الصحف الاخرى في تعاطيها مع القضية بانها كانت اقل حيادية واثرت على مقالاتها عند الحديث عن اصول الولاية، فكانت تنادي بانها "عربية" ففي مقالة لها بعنوان (صراع ام الربيعين) في عددها الصادر في 22 تشرين الثاني 1923 خاطبت العراقيين بان الولاية تدعوهم " باسم عروبتها الحقة الى نجدتها" فهي حسب وصفها "عربية في منشأها، عربية في ادوارها التاريخية، عربية في أقواها، عربية في لنتها"(6). إلا انها تعود وتؤكد على ان اغلب سكان الولاية هم من الكرد في عددها الصادر في 18 أيلول 1924، حيث ذكت في افتتاحيها 


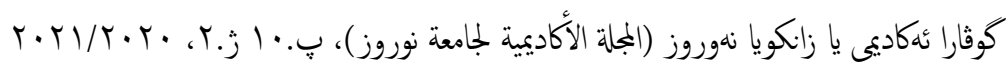

بعد أسبوع واحد من عقد المؤتر، ، اشارت جريدة (المفيد) في عددها الصادر في 25 ايار 1925 المى ان البريطانيين متمسكون بحق العراق في ولاية الموصل اكثر من

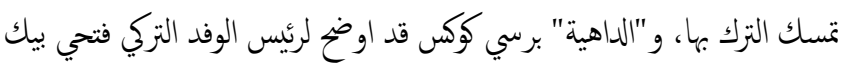
"ببراعة وكياسة" انه سيكون لمجلس عصبة الأم الكلمة الاخيرة في حل الملاف على لى

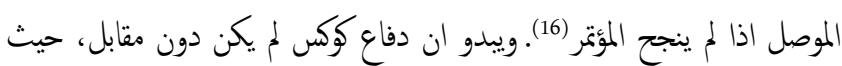
ذكت جريدة( المفيد) في عددها الصادر في 28 أيار 1924 بانه حصلت على برقية من برسي كوكس وهو في إسطنبول يذك فيها أن الأخبار الواردة عن العراق والتي تتعلق بموقف المجلس التأسيسي العراقي وتردده في عقد معاهدة سنة 1922 قد بد شجعت الحكومة التزكة على تمككها في موققها فيا يتعلق بولاية الموصل، مذكراً بانه رغز ذلك فانه "مصر كل اصرار" على التمسك بحفظ حقوق العراق (17)، ويبدو ان برسي كوكس اراد من برقيته ان يؤثر وان يغير شيئا من المواقق السلبية تجاه المعاهدة

كان الوفدان التركي والبريطاني قد اتفقا على عدم تسريب ما يجري داخل قاعات الاجتماعات، فأشارت جريدة (المفيد) في عددها الصادر في 9 حزيران 1924 بان الصحف ولكي تسد الفراغ الحاصل على عدم حصولها على معلومات وتفاصيل المناقشات داخل المؤتر ، أصبحت تراقب حركات برسي كوكس ومواعيده وزياراته حتى في أوقات غداهه وعشاءه، وقد نقلت الجريدة في العدد نفسها على لسان حال الحكومة التزكية كما وردت في جريدة الجمهورية التزكية بان البريطانيين قد عرضوا على الوفد التزكي التنازل عن ثلاثة اقضية من ولاية الموصل لتزكيا، اله انها عادت ونفت عن لسان احد المندوبين البريطانيين هذا الخبر (18)، وذكرت بان (فتحي بيك) قد عقد اجتماعا وصفته جريدة المفيد ب"الخطير" في الخامس من حزيران حول قضية الموصل فقرر فيها رفض قبول الشروط البريطانية لرفع الملاف الى عصبة الهم (19.). اشارت جريدة( العراق) في عددها الصادر في 9 حزيران 1924 الى تفاصيل لم تنشر من قبل عن مؤتمر الاستانة، فذكرت أن الطرفان قد عرضا حججاً تاريخية وجغرافية وعسكرية حول احقية الولاية لما، كما اوردوا احصاء لتأييد رأمها، وكان الجانب البريطاني قد صرح ان الاحصاء الذي قدمه الاتراك عن الولاية غير صحيح، وهو كان قد وضع "للخدمة العسكرية"، فلم يذكر فيه الاشخاص الذين لم يكن لمم علاقة بالخدمة العسكرية، واستند التزك في احصاءهم على ان سكان ولاية الموصل اكثر هم من الترك والكرد، حيث يؤلفون (85\%) من عدد سكان الولاية، وانه لايجب احتساب (180) الف بدوي في الولاية لانهم من القبائل الرحل المتنقلة، اله ان الجانب البريطاني اكد بان العرب لا يبلغون في الحتيقة سوى ربع سكان الولاية بالرغ بعز
بانها "لا تكلف الاتزاك مشاقة عظمة في سبيل قتلها او دفها"، والسبب يعود حسب تعبير الجريدة المى "حداثة عهدها بالرقي" ولذلك سرعان ما "انتضوا عليها الاتراك" واصبحت اليوم همددة بالانقراض في المنطقة التي تقع تحت سيطرته أي: داخل حدود التزكة-كما إن الأمر الذي ساعدهم في القضاء عليها هو عدم وجود الوسائل اللازمة لتدريس اللغة الكردية في كردستان، الأمر الذي اضطر المأمورين الكرد والوجماء والأشراف وطلاب المدراس من الجيل الجديد المى التحدث والكتابة باللغة التزكة، مؤكداً بان قليلاً ما تصادف "وجيها كرديا" او "هذبا" الح وييدا اللغة التركية كاهلها، اما في ايران فان الكرد حسب الجريدة يجيدون اللغة الفارسية "باعتبارها أيضاً لغة البلاد"، وتسلط الجريدة الضوء على ان ما يفرق الكرد في العراق عن الكرد في ايران وتركيا، بانه لن ترى من يحسن العربية نهم سوى القاطنين في المدن العربية او المتزددين عليها كثيرا أو علماء الدين(8). 2. مؤتمر استانة (القسطنطينية) 1924

كانت من نتائج معاهدة لوزان فيما يتعلق بمشكة الموصل، إعطاء الطرفان-بريطانيا وتركيا-همالة تسعة اشهر بهدف الوصول الى حل يرضي الطرفين، ولأجل ذلك عقد في إسطنبول مؤثمر في 19 ايار 1924، مثل الجانب البريطاني برسي كوس( Percy (Cox (9)، المندوب السامي البريطاني السابق في العراق وقد رافقه (طه الهاشيم)(10) رئيس اركان الجيش العراقي بصفة مستشار ، اما الوفد التزكي فكان يترأسه (فتحي بيك) رئيس مجلس النواب التركي(11). من أبرز الصحف العراقية التي تطرقت إلى أعمال هذا المؤتر جريدة (العراق) التي ذكت في عددها الصادر في 29 نيسان 1924 أي قبل المؤتمر انعقاد المؤتمر ، وكتبت بانه سيعقد مؤتمر لبحث قضية الموصل في اسطنبول، الها أنها توقعت بانه سوف لن يتم التوصل إلى نتيجة تزضي الطرفين وذلك اعتاداً على مصادرها التي استندت الى تمكك بريطانيا بالولاية، كذلك اتباع تركيا "سياسة العناد" في مطالبهنا بالموصل (12)، كما أشارت في عدد اخر صادر في 21 ايار 1924، اي بعد عقد المؤتمر بيوم، المى ان برسي كوكس والوفد المرافق له قد وصلوا في 16 أيار 1924 إلى اسطنول استعدادا للمشاركة في أولى جلسات المؤتمر (13)حول مشاركة العراق ضمن الوفد البريطاني ذكرت جريدة (المفيد)(14) في عددها الصادر في 15 حزيران 1924 بان العراق أراد ان يمثلها طه الهاثمي ليدافع عن حقوقها ومصالحها، إلا أن الأتراك رفضوا ذلك ولم يعترفوا بتمثيل للعراق في المؤتر ، مما دفع بالبريطانيين الى ان

$$
\text { يتم تعريفه بصفته مستشاراً في الوفد البريطاني (15). }
$$




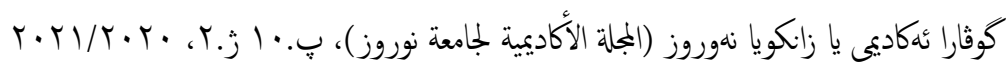

ليس من عادة الاتراك ان يحلوا المشاكل مع غيره عن طريق المفاوضات، بل انهم تعودوا على سلاع الهحكام القاطعة التي تصدرها عليهم في المؤترات او محاك السلام (28).

مثل الجانب التركي في لجنة عصبة الأمكل من (فنحي بيك) رئيس مجلس الوطني التركي الذي كان رئيس الوفد التركي في مؤمر الاستانة، وشكري بك نائب المجلس الوطني من مدينة أزمير حسبا أوردتها جريدة (الأوقات البغدادية) في عددها الصادر في 5 أيلول 1924(29)، اما الجانب البريطاني فكان يترأسه اللورد بارمود (بامور ) مندوب بريطانيا في مجلس عصبة الام، و(برسي كوك) رئيس الوفد البريطاني في مؤتمر الاستانة، استناداً إلى الخبر الذي نشرته جريدة (الاستقلال)

$$
\text { في عددها الصادر في } 30 \text { أيلول 1924(30) }
$$

نشرت جريدة (العالم العربي) في عددها الصادر في الثلاثين من ايلول1924 حول المفاوضات التي جرت في جلسة عصبة الأم الخاصة بمشكة الموصل التي تمت في 15 ايلول 1924 بأن رئيس الوفد التركي فتحي بك اكد بأن تركيا لن تكف عن المطالبة بحقوقها في الموصل التي يقطنها اكثرية من" الترك والكراد"، وان بلاده

مستعدة لقبول اي حدود تقرر على اساس استفناء سكان الموصل (31). بيناكانت الجلسات مستمرة في جنيف بهدف الوصول الى حل لمشكلة الموصل، وقعت بعض الهجات على المناطق الحدودية بين تركيا وولاية الموصل، أُتهم الأثراك من قبل بريطانيا على أنهم هم المسؤولون عنها، ونقلت جريدة (الاستقلال) في عددها الصادر في 1 تثرين الوول 1924 خبراً بهذا الخصوص عن جريدة (ديلي تلغراف The Daily Telegraph) البريطانية بان الهجات على المناطق التي تقع تحت وصايتهم من قبل الاتراك تهديد تمهيدي "لأمر اعظم" ستقدم عليها تركيا، اذا لم تحصل على ما تريده في مسألة حسم الحدود، وشبهت الجريدة هذه الهجات بالتي كانت تقوم بها تركيا على حدودها مع سورية اثناء حدوث مفاوضاتها مع فرنسا(32). بسبب اصرار الطرفين على موقفه تجاه مشكلة الموصل، قررت عصبة الام في جلستها المعقودة في 1 تشرين الوول 1924 تشكيل لجنة مؤلفة من ثلاثة اعضاء لمعاوتتها في البت بهذه المشكلة(33)، وهمة هذه اللجنة كانت جمع المعلومات والتقارير المتعلقة بولاية الموصل وبأصل المشكلة، وكذلك أعلنت بأنها ستقبل من كلا الطرفين-البريطاني والتركي- ما يعرضان من الوثائق وأوراق حول الموصل حسب خبر نشرته جريدة (الأوقات البغدادية)(34) في عددها الصادر في 7 تشرين الاول
من انهم يقولون بان عددهم يبلغ ثلثي عدد سكان ولاية الموصل، وبان المناطق الواقعة غربي نهر دجلة عربية برمتها، اما عن الكرد فكان البريطانيون قد اكدوا بانه وان كان هناك اختلاف (حول اصلهم) الا انهم يختلفون عن الترك اختلافاً بيناً، وبانهم يعارضون دائما تدخل الاستانه في شؤونه، ولم تكن لتركيا سلطة فعلية قط في جنوب كوردستان (20). كان الهوة بين الطرفين شاسعة جداً حسب جريدة (المفيد) في عددها الصادر في 30 حزيران 1924، فاصر الطرفان على المطالبة بالولاية واصبح التأليف بينها مستحيلاً. حسب وصف ككس- مما جعله يقترح تحويل المشكلة الى عصبة الام عملا بنصوص

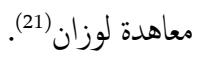

\section{3. عصبة الام ومشكلة الموصل}

بعدما لم يستطع الطرفان، البريطاني الذي مثل العراق في مؤتمر استانة، والأتراك الوصول إلى تفاهم لحل مشكلة الموصل، اشارت جريدة (العالم العربي)(22) في عددها الصادر في 17 تموز 1924، بان رئيس المكومة البريطانية ووزير خارجيتها رامزي مكدونالد(Ramsay MacDonald) قد ارسل إلى الحكومة التزكية مذكرة شرح فيها وبحة نظر حكومته بخصوص الموصل، اقتزح فيها يكية عرض القضية على عصبة الام، مطالباً في الوقت ذاته معرفة وبجة النظر التركية هبذا الخصوص(24)، وفعلاً اقدمت الحكومة التزكية على الطلب من عصبة الام ان يضع قضية الموصل في جلسة العصبة التي ستعقد في 19 أب 1924، حسب ما اوردتها جريدة المفيد في عددها الصادر بتاريخ 15 تموز 1924(25). تطرقت جريدة (العالم العربي )في عددها الصادر في 26 اب 1924 ان الحكومة التزكة ترفض احلالة قضية الموصل المى عصبة الأم وهي تريد أن تكون هناك مفاوضات مباثرة بهذا الخصوص بينها وبين بريطانيا دون اللجوء الى عصبة الام (26)، اله انه يبدو انها تراجعت عن موققها فيا بعد ووافقت على عرض القضية على العصبة حسب جريدة العراق التي أوردت هذا الخبر في عددها الصادر 3 أيلول 1924، فقد ذكرت بان الحكومة التزكية ابرقت الى مجلس العصبة بقبولها مبداً التحكيم في قضية الموصل (27). عُدت الصحافة العراقية تحويل مشكلة الموصل إلى عصبة الام انتصاراً للسياسة البريطانية، فذكرت جريدة (المفيد) في عددها الصادر في 3 ايلول 1924 بانهم اول من عرفوا بان صفة العناد التي عرف بها الاتراك في بداية كل مفاوضات لا يككن "ان ينخدع" بها الساسة البريطانيون، الذين حسب وصفها يعرفون الترك واخلاقهم وطباعهم اكثر ما يعرفه عنه غيرهم، وهم -أي: البريطانيين - قد وصلوا إلى نتيجة بان 


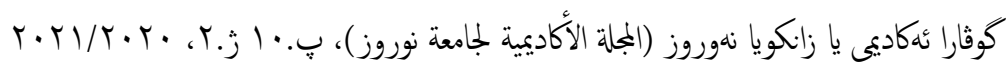

الامة الكردية العراقية ستصبح بفضل تمتعها بالحرية منثق النور لكردستان"، وهم - أي: الأتراك- يريدون إطفاء هذا النور قبل ان "تلامس اشعتها عيون كردستان الكبرى، فتنفتح وتلامس أرواحا فتنعشها فتنهض"، ويتسأل الكاتب لماذا لا يصرح الانراك علانية بأنهم لا يستطيعون رؤية اللغة الكردية تدرس في المدارس؟! وهم برأيه لن يتحملوا أن يروا الكرد في العراق قد حصلوا على "حقوقهم المشروعة"، ثم بهري ينهني مقالته بأن الأثراك يخافون من أن الشعور القومي الكردي الذي اخذ "يمو ويترعرع ويحترم ويقدس" في العراق سيشكل "النواة الكردية" التي ستؤدي إلى فشل سياسة الأتراك في فرض التزيك على الكردد39).

4. - الأعال الحتامية للجنة عصبة الأم

وصلت لجنة عصبة الام في 18 كنون الثاني 1925 المى العراق، فكانت بغداد اولى محطاتها، وذلك حسب خبر نشرته جريدة (الموصل)(40) في عددها الصادر في 19 كانون الثاني 1925(41)، وبعد ايام قضتها في العاصمة، وصلت اللجنة الى مدينة الموصل وذلك بتاريخ 29 كانون الثاني، أجرت اللجنة فهيا عدة مقابلات وزيارات ميدانية في المدينة واقضيتها(42)، ثم زارت مدينة السليمانة، وكركك، واربيل، وعادت الى الموصل في 7 اذار 1925(43). انتهت اللجنة من كتابة تقريرها، وكان من المؤمل ان تقدمه الى مجلس عصبة الوم في اجتاعه الرابع والثلاثين في حزيران 1925، ولكنها استمرت في كتابة مسوداته حتى 16 تموز 1925(4)، وقد ارسل مجلس العصبة بنسخة منه الى كل من المكومتين البريطانية والتركية في 18 تموز 1925، ومختصر ما وصلت إليه اللجنة عن مصير ولاية الموصل انه اذا اخذت مصاح السكان بنظر الاعتبار فهي تعتقد انه من المفيد إلى حد ما تقسيم ولاية الموصل بين العراق وتركيا، وهي ارتأت ان الحجج المهمة، ولاسيا الاقتصادية والجغرافية، وعامل اكثرية السكان ، تميل لتأييد ضم جميع الأراضي الواقعة جنوبي خط بروكل (45) إلى العراق، وذلك بشرطين، الأول: تبقى هذه الأراضي تحت الانتداب البريطاني لمدة خمسة وعشرين سنة، والشرط الثاني: ان تأخذ بنظر الاعتبار رغبات الكرد بتعين موظفين كرد في المحاك والمدارس، وبأن تكون اللغة الكردية، اللغة الرسمية فيها، كما اكدت اذا قرر مجلس العصبة تقسيم الاراضي المتنازعة، فأنها تعتقد ان افضل خط هو الذي يمتد مع الزاب الصغير (46) . عقب صدور التقرير، هاجته الصحافة العراقية، فقالت جريدة (العراق) في عددها الصادر في 13 أب 1925 عنه بأنه "اخرق"، وبأنه لا يؤيد رأي البريطانيين، كما

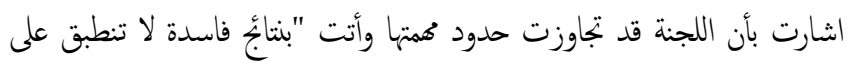
العمل والمنطق" (47)، كا اتهمت جريدة (العالم العربي) في عددها الصادر في 15 أب بهرب
مع الاهتمام المستمر للصحافة العراقية بمتابعة ملف مشكلة الموصل، وتغطية جلسات عصبة الام المتعلقة بها، كانت بين الآونة والأخرى تنشر أخبار ومقالات عن الكرد باعتبار هم العنصر الأهم والأكثر في الولاية، فحاولت خلق صورة للرأي العام العراقي مفاده أن الكرد يريدون الانضام إلى المملكة العراقية، ويرفضون الحاق ولاية الموصل بالدولة التزكة، فنشرت جريدة (المفيد) في عددها الصادر في 8 تشرين الاول 1924 مقالة للكاتب(فتح الله - من بغداد) بعنوان(كردستان الجنوبية والترك)، أنشار فيها الكاتب الى ان "المة الكردية" قضت عصوراً عديدة تحت سلطة الانراك، الذين كانوا يمارسون "سياسة الفوضى" في "ركدستان" ما دفع بالكرد إلى القيام بثورات الذين -حسب وصف الكلب-" فطروا على الحرية وحب الاستقلال" ورفضوا العيش تحت سلطة الانراك، وبهدف الحصول على تعاطف كردي، يتسأل الكاتب: هل ينذكر الكورد "حكومة كردستان العزيزة"!! التي قضى عليها التزك، وحولوا "العزة بالنذل والعمران بالحزاب، والراحة بالفناء"، وهل سيرضى "الكراد" بارجاع

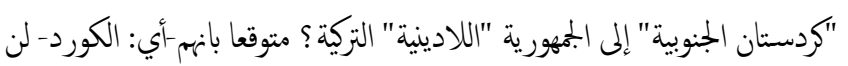
يقبلوا بذلك، لانهم يعرفون بان اخوانهم "الكواد الشماليين يذوقون اشد العذاب"(36) من القتل والتهجير ، وبانهم يعرفون حق المعرفة بان بقائهم مع تركيا ستكون نهاية "قوميته"، ، حيث سيتم انصهار هم ضمن العنصر التركي (37). وعلى المنوال نسه، نشرت جريدة (الاوقات البغدادية) في عددها الصادر في 25 تشرين الثاني 1924، بان سكرتير عصبة الام قد استلم مذكرة من العشائر الكردية القاطنة في ولاية الموصل، بينوا فيها احتجابحم الشديد ضد "ادعاءات الأتراك" حول حقهم في ولاية الموصل، موكدين بأنه "لاحق" لم فيها، لا من الناحية الاقتصادية ولا السياسية ولا العنصرية(38). كذلك نشرت جريدة (العالم العربي) بهذا الصدد في عددها الصادر في 3 شباط 1925 مقالة للكاتب (موصلي) بعنوان( قضايا حدودنا...تركية تضمر للأكراد الفناء المبرم. فلتفتح اللجنة الامية عيونها لترى كل شيء)، ذك فهيا الكاتب عن حاجة الكرد من الناحية الاقتصادية الى العراق العربي، اكثر من حاجته الى تركيا، فيتسأل ماذا يكون مصير أي شبر "ينسلخ عن العراق" غير "الفقر ، والخزاب، والدمار"،

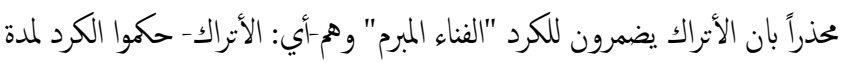
قرون وجعلهم في "حالة البؤس والشقاء"، وهم الآن حسب رأي الكاتب "امة شديدة ذات بأس وقوة" يخشاها الأتراك، ويخشون من ان يصبحوا خطراً عليهم، ويضيف بان سبب خوف الأتراك من انضام الكرد إلى العراق، هو انهم يخشون

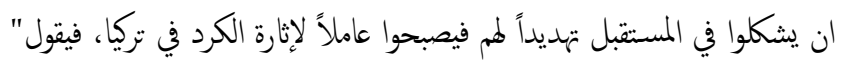




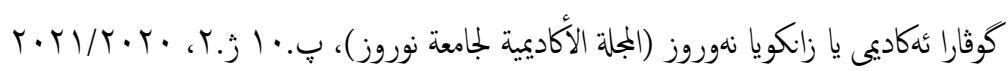

أكدت المحكة على أن يكون قرار مجلس العصبة باتفاق الآراء، وعدم مشاركة مندوبي

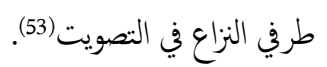

وبعد سلسلة من الاجتماعات والمناقشات، اصدرت عصبة الام قرارها النهائي حول مصير ولاية الموصل في 16 كانون الاول 1925 الذي اعتبر خط بروكسل خط الحدود بين العراق وتركيا، وبها القرار أصبحت ولاية الموصل رسميا جزءاً من العراق، وقد ادى القرار المى موجة من الفرح والشعور بالنصر ترجم على صفحات الجرائد العراقية، فاعتبرت جريدة العراق في عددها الصادر في 18 كانون الاول 1925 اصدار القرار بانه "فوز العراق الككبر"(54)، وفيها يتعلق بالكرد، أشارت جريدة (الاستقلال) في عددها الصادر في 18 كانون الاول 1925، الى ان عصبة الام قد اوصت بريطانيا بصنها الدولة المنتدبة للعراق، ان تبسط التدابير التي تتخذ

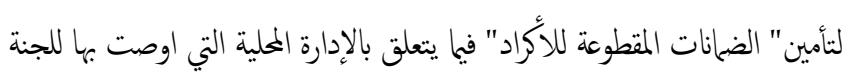

\section{التحقيق في استنتاجاتها النهائية(55).}

هكذا انضم جنوب كردستان أو ماكانت تعرف حينذاك بولاية الموصل، إلى مملكة

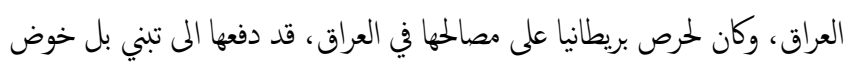
معارك دبلوماسية واستخدمت فهيا مكانتها العلمية، من اجل ضم ولاية الموصل الى لى العراق، وكان العنصر الغائب في هذه المفاوضات المباشرة والغير المباشرة، هم الكرد أصحاب الأرض الذين عانوا من التشتت والاتقام، وحاول طرفي النزاع، استخداهم وفق ما يخدم مصالحهم، كما أن توقيت البت في القضية ساعد العراق والبريطانيين على إثارة الكرد وكسبه في صفوفهم بسبب قع الأتراك للكرد في تركيا وذلك عند اندلاع انتفاضة الشيخ سعيد بيران شباط-نيسان 1925 التي كانت متزامنة أعمال لجنة عصبة الأم وقراراتها.

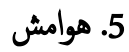

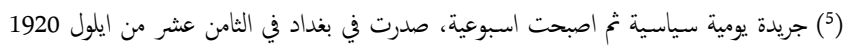

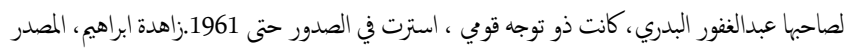

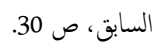

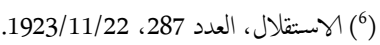

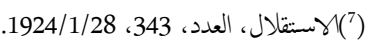

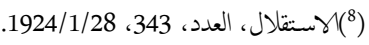

(9) برسي وكس (1864-1937) سياسي و عسكري بريطاني ،التحق بالجيش عام 1884 ، 1843 ، انضم الى ادارة

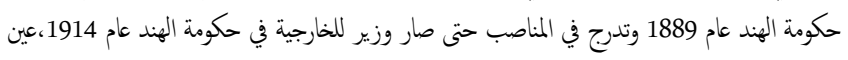

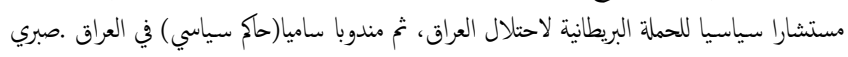

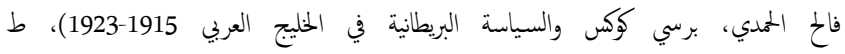

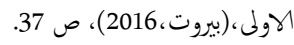

1925 عضو اللجنة (الكونت المجري) بأنه لم يكن محايداً، وكان منحازاً الى الأنراك، و دافع عن النظرية التركية فيه يخص مصير الولاية(48). وبينا كانت عصبة الام مستمرة في عقد جلساتها لبحث ما ورد في تقرير لجنتها بشان ولاية الموصل، وقعت حوادث هجات على حدود ولاية الموصل مع تركيا مجدداً، وحول هذا الامر، اشارت جريدة العالم العربي في عددها الصادر في 18 ايلول 1925 بان السلطات البريطانية في العراق أرسلت إلى مندوبها في جنيف تقريراً يتضمن تفاصيل الهجات التي شنها الاتراك على القرى المسيحية في منطقة (الكويان)(49) في 9 أيلول 1925(50)، مما دفح عصبة الام الى ايفاد لجنة برئاسة الجنرال ليونر(Leoner) الى المنطقة بهدف التحقيق في الاحداث التي وقعت على خط بروكسل، واعلام العصبة بالتطورات التي ادت الى تلك الخزوقات، وقد وصلت اللجنة إلى مدينة زاخو الحدودية في 13 تشرين الثاني 1925(51). في عددها الصادر في 4 تشرين الثاني 1925، اشارت جريدة (الاستقلال ) انه قبل ان تقرر عصبة الامم قرارها النهائي بشان ولاية الموصل، وبهدف اضفاء الشرعية على قرارها، اقدم مجلس العصبة على دعوة محكمة العدل الدولية في لاهاي لإبداء رأهيا في مسألتين قانونيتين، تتعلقان بموقف العصبة من الخلاف القائم في مشكلة الموصل بين بريطانيا وتركيا، الأولى: تمثلت بنوع القرار الذي يجب على مجلس العصبة ان يصدره حول القضية، وهل يجب ان يكون حكماً نهائياً او توسطا؟ والمسألة الثانية: فكانت تتضمن سؤالاً حول طريقة اتخاذ القرار، هل يكون بالأكثرية؟ وهل

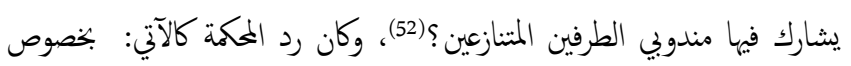
المسألة الأولى، هو انه يجب اعتبار مجلس عصبة الام الحكى وليس الوسيط، لذلك اي قرار تصدره، يجبر طرفا النزاع على الرضوخ لحكها، وبخصوص المسالة الثانية،

(1) وقعت في الثلاثين من تشرن الاول 1918 ، بين الحلفاء والدولة العثانية على ظهر الباخرة البريطانية

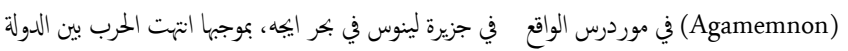

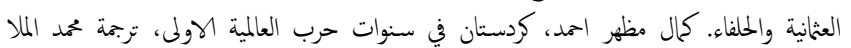

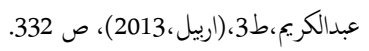

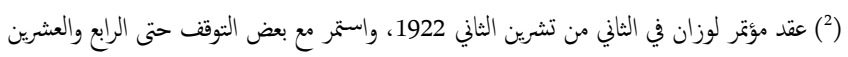

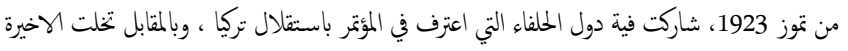

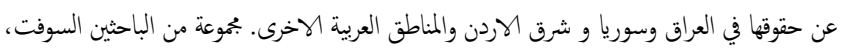

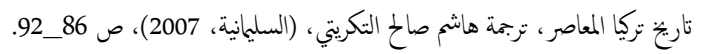

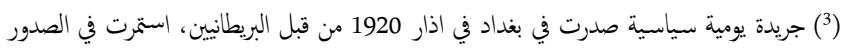

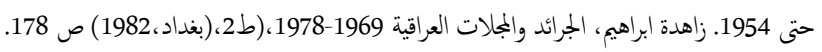

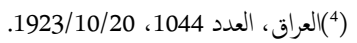




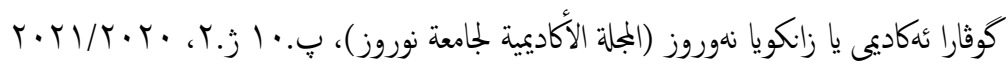

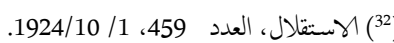

(10) ولد في بغداد في شباط 1888، انهى دراسته العسكرية في اسطنبول 1909، عاد الى بغداد 1922،

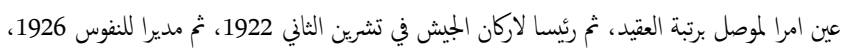

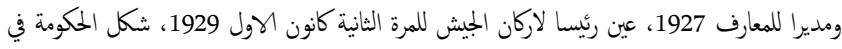

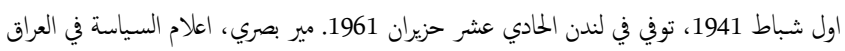

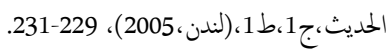

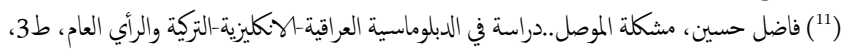

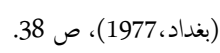

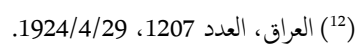
(13) العراق، العدد 1226، العراق، العدد، 1207/4/21)

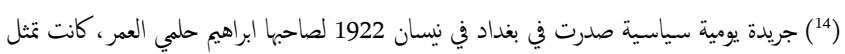

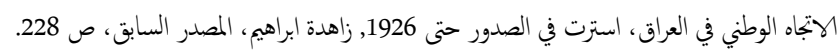

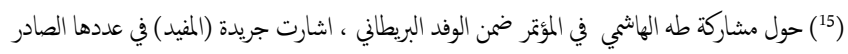

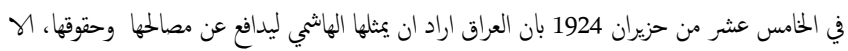

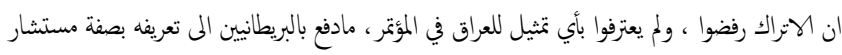

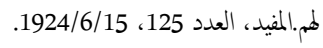

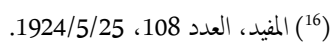

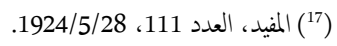

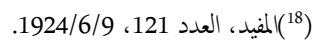

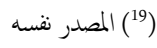

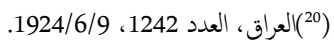
(21) المفيد، العدد 137، 16/30/ 1924. نصت العقد 1242/6/9 الفرة الثانية من المعاهدة في ما يتعلق بقضية الموصل"

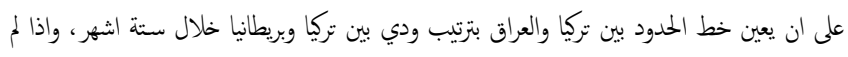

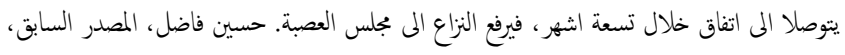

ص 40 (22) جريدة سياسية يومية صدرت في بغداد في اذار 1924 لصاحبها حسون ومراد، استمرت في الصدور

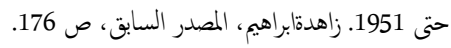

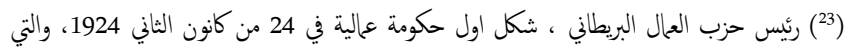

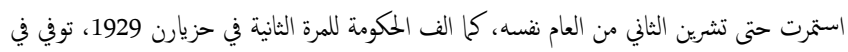
عام 1930: بنظر Encyclopedia Britania, Vol, 10, London, 1967, p.160.

$$
\begin{aligned}
& \text { (24) العالم العربي، العدد 97، 1924/7/17) } \\
& \text { (25) المفيد، العدد 171، 1924/8/15. }
\end{aligned}
$$

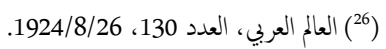

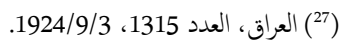

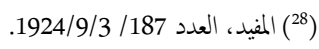

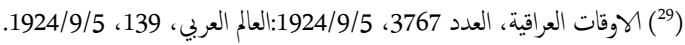

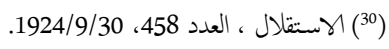

(31) (العالم العربي، العدد 160، العدد 19/30/ 1924.

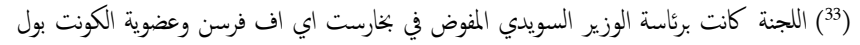

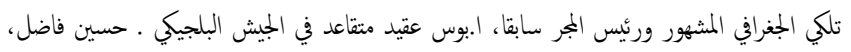

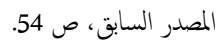
(34) جريدة سياسية يومية صدرت في بغداد في كانون الثاني 1918 من قبل البريطانيين واستمرت في

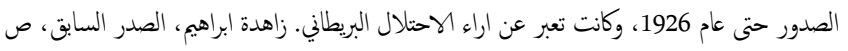

(35) الاوقات البغدادية، العدد 3794، 10/7 (34) 1924.

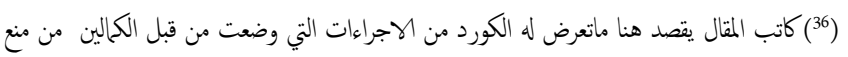

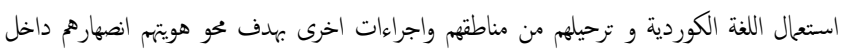
العنصر التركي .

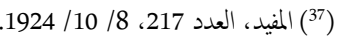

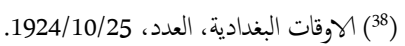

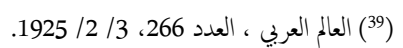

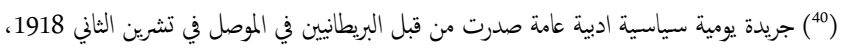

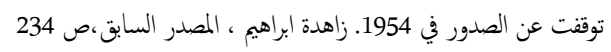

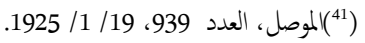

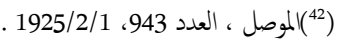

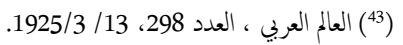

(54)

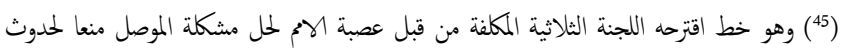

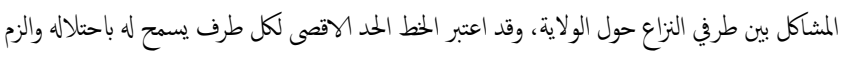

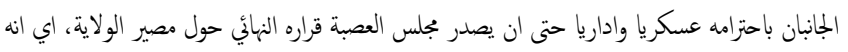

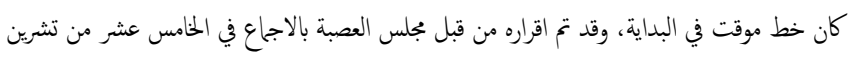

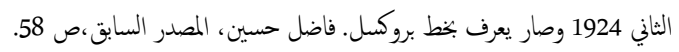

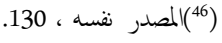

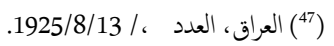

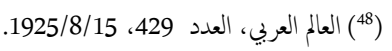

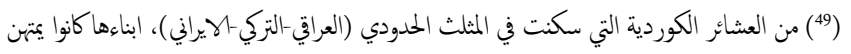

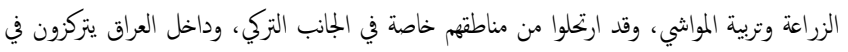

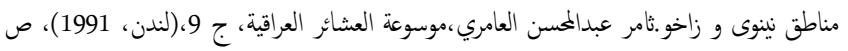

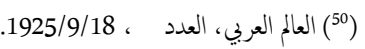

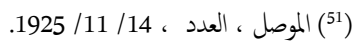

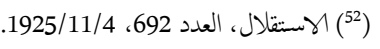

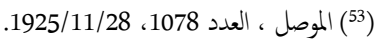

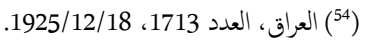

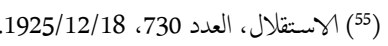

